\title{
Smart Investment Management System - A sustainable open source solution for attracting investment in Oman
}

\author{
Reem Khamis Mohammed Allawati ${ }^{\mathrm{a}}$ and Dhanalakshmi Venugopal ${ }^{\mathrm{a}}$
}

The investment is very necessary activity in any country which plays an important role to improve the countries social and economic status. Investment will also help in the identification of the most important industrial areas in the country, which will help in promoting country and activating other state sectors, such as tourism sector. Considering the current economic situation of the Sultanate, It is evident to conduct study on alternate resources to boost the economy. Nowadays, most of the people prefer to use new technologies which help them to complete their work easier and smarter. The most important reason for this research paper is to study the possible innovations in investment area and building application for investment is to meet the needs of the investors.

Keywords- PEIE, Investment, Investors.

\section{INTRODUCTION}

The Public Establishment for Industrial Estates was established in 1993. It plays a prominent role in promoting the location of the Sultanate of Oman in the industry through communications, initiatives, innovation and excellence by attracting investments, introduction of the modern technology, giving the workers technical skills that are needed to improve their production and development of international trade. It thus aims to achieve the objectives of the development plans and future vision of the Omani government (Oman 2020). The establishment invites the investors from within and outside Oman to start investing in industrial zones and it is committed to providing all facilities, incentives and continuity in providing excellent services.

\section{CURRENT SYSTEM}

The Public Establishment Industrial Estates have an online system which provides some services for the investors such as PEIE map that is used to manage and view PEIE locations such as estates, land, buildings, office and view tenants who invest in these locations. In addition, the current system provides an investor's guide which helps the investors to have an overview and knowledge about the investment process. Also, it provides tenant directory which list the tenants, their estates, business activities and contact information. Staff and investors can access the system to see their details. In addition, the current system has some services such as providing training for companies and factories.

The current system of PEIE, makes it difficult for investors to use because not all the investors have enough experience in using the computer and accessing the current system. On the other hand, some of them do not have enough time to use the computer and access the system because they are always busy with their business and also because they are frequently travel. Consequently, it is very difficult for them for carry a laptop everywhere. Therefore, it is necessary to develop and to design an application for the investors that will be easy for them to use and access any time. In addition, as the economy of the country is slowing down, it is very important to think and do something to increase the growth of the economy. Thus, this application will help to activate the investment sector and expand the economy of the country.

\section{Literature Review}

- Increase the economy of country:

According to the research done by E.Borensztein et al (1998), foreign investment affects the economy of the country directly. Studies confirm that foreign investment is an important tool for growth, development and increasing the economy of the country, linking investment with technology. Technology plays an important role in the provision of 
new varieties of capital goods and multinational companies, which make more progress.

The proposed application will attract the forging investment to start investing in their projects in the PEIE. Therefore, the profits of the establishment will increase so the economy of the country will also increase directly.

\section{- Secure mobile application database:}

The author discusses in his article the importance of having secure database for mobile to avoid any threats by unauthorized users. He mentions the importance to provide strengthen the encryption of data in the database. Databases containing confidential data it can access by a variety authorized users. In addition, all the data must be available for authorized users at any time (Bhagat.A.R1, 2014).

The Paper helps to select strong database to save the confidential data safely for designing and developing secure application for the investor management system. Back 4 App database will be used which will help to protect the database from the different threats.

It is very necessary to determine the needs of the project before building the application to be clear about the requirements. To resolve the problems faced by the PEIE, investors and the country in general need an easily accessible application that is easy to understand. In other words, this application will be very useful for the PEIE to increase the profits of the establishments and attract more and more investors from within and outside Oman. This will also help in the identification of the most important industrial areas in Oman, which will help in promoting Oman and activating other state sectors, such as tourism sector. Thus the growth of the economy in the country will be enhanced and this especially important, Considering Omani economy is going through. The most important reason for building this application is to meet the needs of the investors which are; they need easy ways to figure out the most appropriate industrial areas to start investing with complete descriptions of it. In addition, they need to complete some of the transactions of the investment process by the application because most of the time investors are busy with their business so they need fast ways to complete the work without having to visiting the offices of the PEIE to complete the investing process; in this context they can use their mobile devices to successfully complete the process.

\section{- Save time:}

Today the whole world believes the words "time is money". This is true no one can deny this principle. If you work in any filed; you earn money because of what you are doing. If you work more you will take more. Nowadays, the industrial services are focused to produce high quality at the lowest cost in a short time. For example, when the company is working to identify their goals well and has good plans, this will save time for the production of larger and larger amount (Lee, 2002).

The enormous and rapid developments in all walks of life have made us unable to keep up with that pace and we are far from what is going on. For that, you should take advantage for the modern technologies to do the work in a short time. The new techniques are very important factors to reduce and manage the time if it is properly harnessed. It can be a factor that will help us to accomplish our work quickly.

The significance of time when saved can be used for other things. A good example for that is mobile phone which can be used to build applications which help will the investors to access the application for the organization, see the details for investment process and then start to invest. Therefore, the investors will save time by using new technology which will help them to do their other work.

\section{- Encourage the member of community to start their business by investing:}

Kritikos (2014) explains in his study" Entrepreneurs and their impact on jobs and economic growth" the effect of the entrepreneurs on economic growth and creating jobs. Entrepreneurs have a huge role in the growth of the economy of the country through the projects they are doing, introducing new products and services which contribute to the increase in productivity of the companies and economies. However, some of the entrepreneurs face some difficulties that lead to failure of the project because of increased costs such as higher tax rates.

It is suggested to attract the entrepreneurs to invest in the government institutions; it must to introduce new technology to facilitate the investment process with provision of some facilitates which might help them to start investing. 11

This study is related to the proposed application will attracts and encourages people to start 
construction new business because the application will provides enough details of the investment process in the PEIE which will help them to take an overview and starting to invest.

\section{PROPOSED APPLICATION}

The proposed application is designed to provide an overview and detailed information about the Public Establishment for Industrial Estates and its policies in the field of industrial areas which are under the directors of the establishment. The application will provide clarification regarding the steps of investment in the establishment and the available chances for investment. Existing investors will be the ones who are targeted by this application, which will enable them to access their account to view the data of any company, information about the investment, employment, capital, products, business activities, products, raw materials and sales data. In addition, investors can access their account to see their details and can update their data. Investors can take an overview about the industrial estates and if he/she is interested to start an investment in the PEIE he/she can complete a form of investment.

\section{METHODOLOGY}

For the proposed subject Dynamic System Development Method (DSDM) will be used because the requirements of the PEIE will keep on changing and the time and cost is fixed. Client will be involved in the project for collecting the important requirements which will help designing and developing of the application successfully. In addition, feasibility study and business study is done before the implementation phase. The simple model will be provided to the clients to take their feedback and start in the real design. For that, the DSDM is very suitable for this project. On the other hand, prototype model is not suitable for the proposed project because the proposed project has fixed time, and in the prototype model time is lost because repairing comes in the way of building the application again. In addition, Spiral model is not suitable for the proposed project because it is very costly and the process is very complex. Also, Waterfall model is not suitable for the proposed project because the requirements of the customers will keep changing, and this model not does allow making changes during the development process.

\section{DATA ANALYSIS}

Thorough analysis of the data collected from the interview, it is clear that, the PEIE needs new technology which will help to attract more investors to start investment in their institution. In addition, they want to increase the profits of their institution which will help to increase the economy of the country. Also, they are trying to solve the problems which are faced by investors when they use the current system. So, they are searching for a way which will save the time for investors and help them to do the investment process successfully and in a short time. For that, the manager of PEIE wants to improve the performance of PEIE to solve the problems which are faced by the investors and increase the profits by attract more investors.

\section{SYSTEM DESINING - Use case diagram}

The use case diagram for the proposed system has two major actors which are investor and manager. There are many use case with different relationships like association like manager can login to the system. The other relationship is directed association like system will show the investor confirmation message after fill the request form. Also, there are extended and include relationships which show in the follow diagram. 


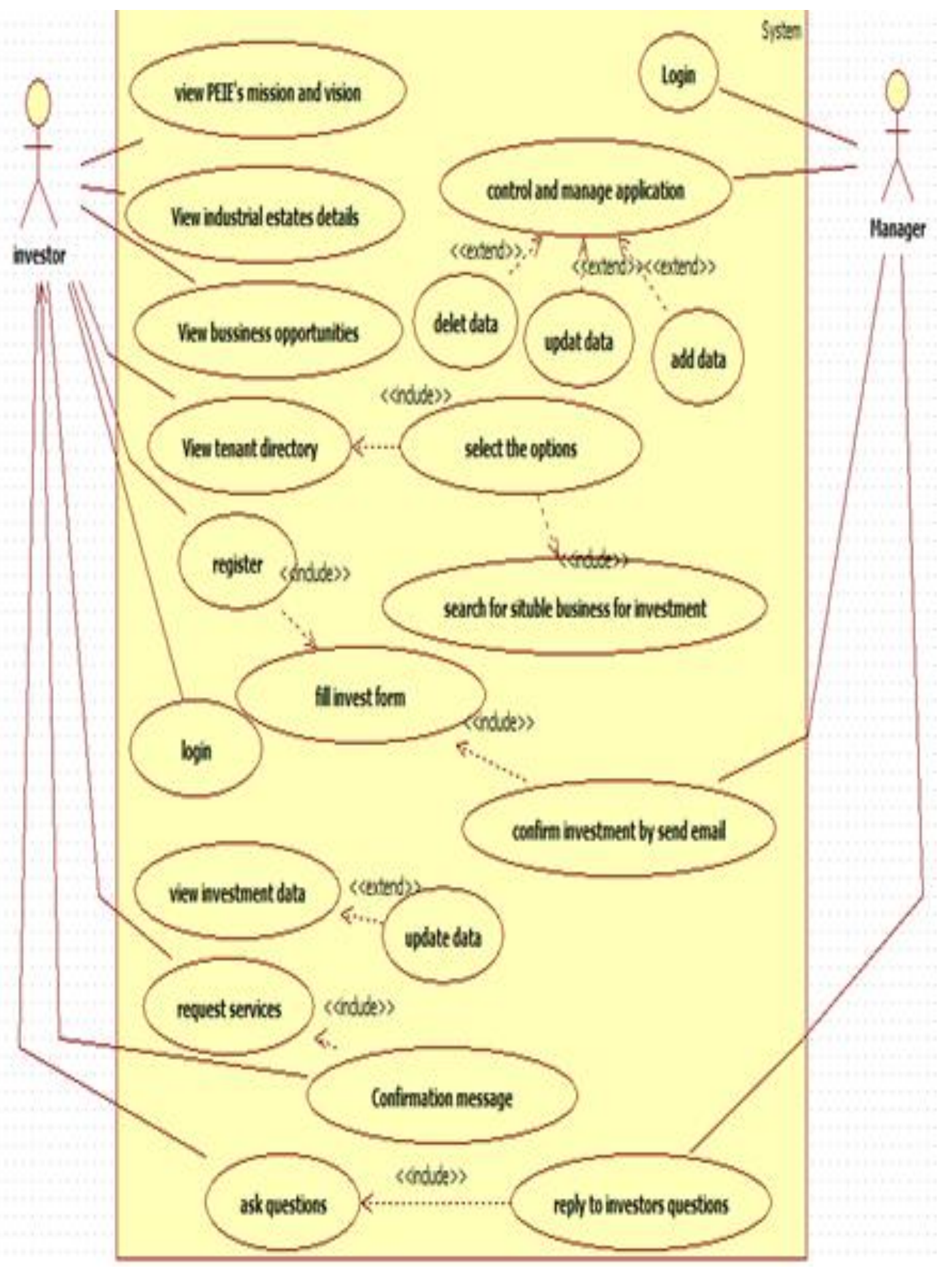

- Sequence diagram:

Figure1: Use Case Diagram

The following diagram shows the sequence diagram for the proposed application. 


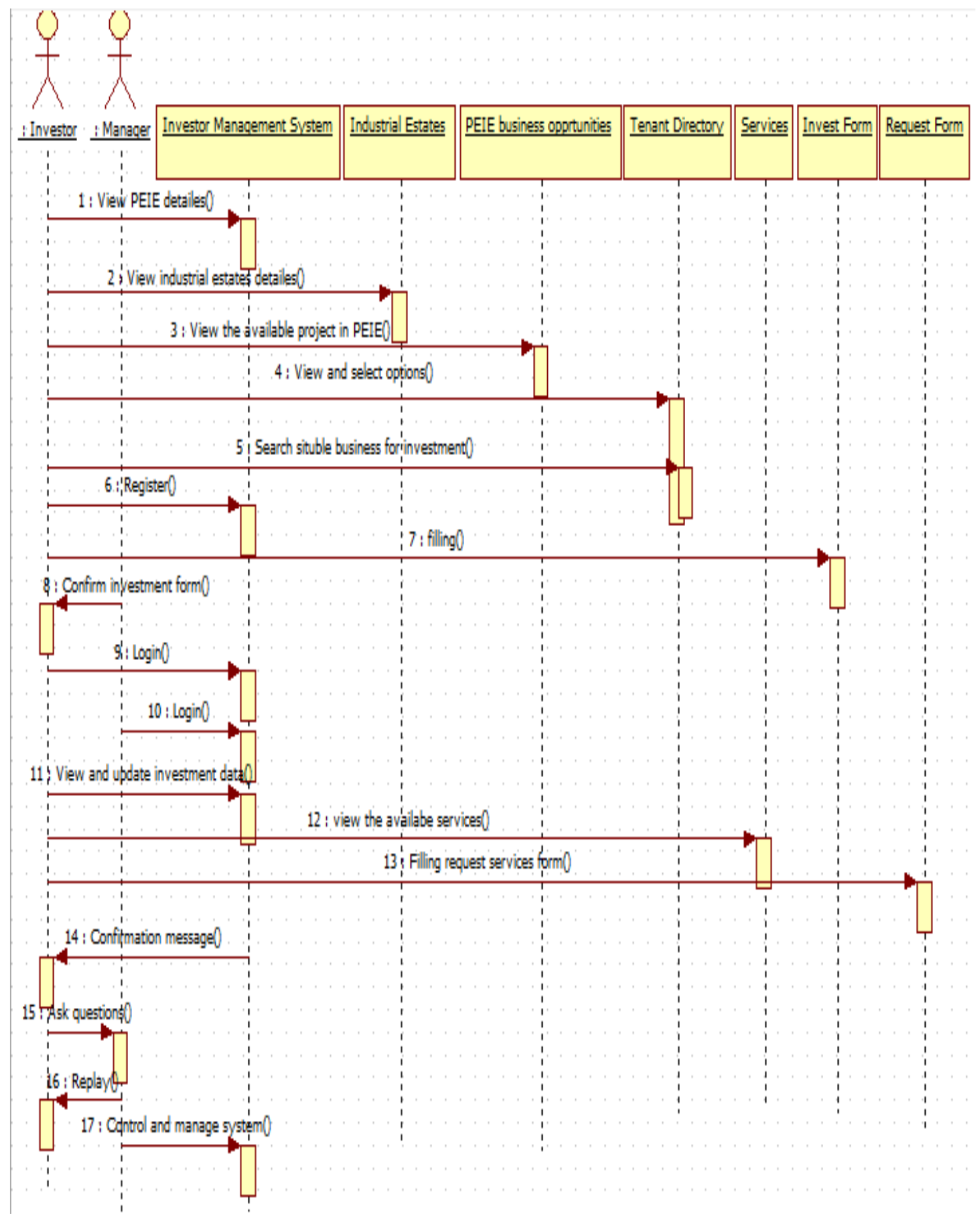

Figure2: Sequence Diagram 


\section{CONCULSION}

Major studies on the related fields are conducted to finalize the need and requirements of a smart investor system, the system not only save time of the investors but it increases the economy of Oman to a greater extends. The smart mobile application also caters to attract more investors and reduce the hassles faced by each of them on the process of investment.

The future research can be carried on the area to provide the applications on different operating system such as IOS. In addition, add another language for the applications like Arabic language to attract more Arabic investors.

The advance and suggestions for the future work to improving the performance and quality is to providing bank transactions in the application to be easy for the investors to complete the bank process by using the application. In addition, allow staff in PEIE to access the application to see their details.

\section{REFERENCES}

Al.ajmi, M., (2016). Investors Management System [Interview] (15 October 2016).

Bhagat.A.R1, P. B., (2014). Mobile Database Review and Security Aspects.International Journal of Computer Science and Mobile Computing, 3(3), p. $1174-1182$.

E. Borenszteina, *. J. D. G. J.-W. L., (1998). How does foreign direct investment affect economic. Journal of International Economics, 45(20431), pp. 115-135.

James, J.,(2009). Acceptance Plan Project Management Template. [Online] Retrieved 6 January 2017. Available at: http://blog.method123.com/2009/08/05/Acceptance-ProjectManagement-Template/\#!prettyPhoto

James, R., (2004). System Development Life Cycle. [Online] Retrieved 8 January 2017 Available at: http://www.hyperthot.com/pm_sdm.htm Kritikos, A. S., (2014). Entrepreneurs and their impact on jobs and. Productive entrepreneurs can invigorate the economy by creating jobs, 22 May, pp. $1-10$.

Lee, H., (2002). Time and Information Technology: Temporal Impacts. The Information Society, 24 April, p. 235-240.

[8] McDonald, M., 2016. 11 Best Apps for Timid First-Time

Investors Retrieved 1 January 2017Available at:

https://www.gobankingrates.com/investing/10-apps-timid-firsttime-investors

Stapleton, J., (1997). Dynamic System Development Method. 7 ed. Cambridge University Press: Addision-Wesley.

Watt, A., (2004). Risk Management Planning. Retrieved on 6 January 2017.Available at:

https://opentextbc.ca/projectmanagement/chapter/chapter-16-risk-

management-planning-project-management/ 